\title{
Legal Risk and Regulation of Peer to Peer Lending Industry in China*
}

\author{
Xiangyu Chen \\ School of Public Affairs and Administration \\ University of Electronic Science and Technology of China \\ Chengdu, China
}

\begin{abstract}
The peer to peer lending has developed rapidly with its advantages of convenience, high efficiency and low transaction costs since its rise in China in 2007. However, many lending platforms have closed down actively, have difficulty in withdrawing deposit, and escape without connection due to the imperfection of the legal system for risk prevention of the industry. This paper analyzes the existing problems in the standardized peer to peer lending industry, and puts forward some suggestions to promote the deguarantee, strengthen data protection and industry supervision, improve the supporting laws and regulations and perfect the dispute resolution mechanism for the platform in order to promote the sound development of the industry in China.
\end{abstract}

Keywords-peer to peer lending; big data; risk prevention; legal supervision

\section{INTRODUCTION}

The mode of peer to peer lending attracts the attention of a large number of financial investors by virtue of its own advantages of Internet finance and the ability to collect a large number of idle funds in a short time. It has played an important role in the field of micro-finance and changed its development trend, to a certain extent, filling the insufficient coverage of traditional finance [1]. The peer to peer lending platform only acts as an intermediary to provide information to participate in the investment and financing of the borrower and lender in developed countries such as Britain and the United States, so investors face less risk of uncertainty caused by the platform. In China, due to the imperfection of the financial supervision system, purposely blurring the distinction between online lending platforms and banks in propaganda, a considerable number of peer to peer lending platforms promote financial investment products as bank deposits to the public on a large scale relying on the lack of public financial knowledge, so that people without investment knowledge often lose all their capital invested, which not only seriously violates the relevant laws and regulations, but also greatly damages the property rights and interests of citizens. In view of the above problems, peer to peer lending ensured the safety of capital flows in the early stage of development through the introduction of a guarantee

*Fund: Phased Outcome of the Youth Project "Legal Governance Research on Peer to Peer Lending Platform from the Perspective of Information Tools" by China Law Society in 2017 (Project No. CLS2017D111). system to stabilize the investors group and achieve scale effect of investment and financing. However, the introduction of this mechanism does not conform to the positioning of peer to peer lending platform as an information intermediary in practice, but also increases the operational risk with a great security problem. In view of the above problems, in August 2018, the National Leading Group Office of Peer to Peer Lending Risk Special Rectification issued a "Notice on the Compliance Inspection of Peer to Peer lending Institutions" in order to promote the reform and innovation of this industry, and at the same time, the relevant legislative system and financial supervision policies should be matched with it, so that it can better promote the sustained and healthy development of China's peer to peer lending industry.

\section{PRACTICE AND DEVElopment OF ChINA'S PEER TO PEER LENDING INDUSTRY}

Since 2005, the model of peer to peer lending, which takes Zopa as a typical example, has made a great stir in the domestic financial market in Britain. The peer to peer lending, with its characteristics of high-yield, has risen rapidly in the world and landed in China in 2007. From 2007 to 2011 , the peer to peer lending, as a new fashion in the financial field, has not achieved explosive effect in China with very limited scope of acceptance and recognition.

The period between 2012 and 2014 is called the coexistence of the expansion and outbreak of risk of the peer to peer lending platform. The peer to peer lending platform in the teeth of the Internet has achieved rapid development at this stage - especially the 2013, known as the "first year of Internet finance", it is the year that Internet finance has gained rapid development and occupied the market share. Compared with the trend of "extensive development" from 2012 to 2014, the development of peer to peer lending industry has decreased from 2015 to 2018 , and the public investment has been rational gradually. The growth rate of the entire industry slowed down, transferring from the "extensive development" to the "normative development".

In May 2018, the turnover and the comprehensive annual interest rate of peer to peer lending decreased from the link relative ratio and year-on-year basis: the turnover of peer to peer lending dropped to 189.588 billion yuan in May 2018, $12.9 \%$ less than 217.666 billion yuan in April 2018, and 
$46.6 \%$ less than 355.064 billion yuan in May 2017; the average comprehensive annual interest rate of peer to peer lending rose to $9.57 \%$ in May 2018, up 0.01 percentage points from $9.56 \%$ in April 2018, but 2.48 percentage points less than the $12.05 \%$ in 2015 at the end of the golden age. What corresponds to this is the growth of the number of lending platforms with problem. As of August 2018, the number of lending platforms that have closed down actively has difficulty in withdrawing deposit, and escape without connection is still growing. Especially in July 2018, there was a centralized outbreak, but the overall growth rate has slowed down.

\section{THE MAIN PROBLEMS AND RISKS IN THE OPERATION OF PEER TO PEER LENDING PLATFORMS}

The development of Internet technology has contributed to a considerable market share of peer to peer lending in China. On the other hand, it also reflects the urgent needs of the public for convenient investment and financing. It is precisely because China has been in a financial depression situation dominated by the traditional financial management and loan business of banks for a long time that investors think that the means of financial management are single but there are no various investment channels. [2] The main body represented by small and medium-sized entrepreneurs has a strong demand for financing. However, loans are not available for them because of many objective external factors such as the storage capacity of bank's credit, reserve ratio, macro-policy and so on. And the amount of private loans is limited by its own capital, so it is difficult to ensure the efficient circulation of funds, [3] which makes borrowers have to resort to other financing channels to seek their own development. In this case, peer to peer lending platform, as a tool to achieve efficient matching of financing needs, gives full play to the convenience of the network and achieves efficiently nationwide lending matching. However, due to the unclear legal position of the institutions and the lack of follow-up legislation, many problems have been exposed and the number of platforms that collapsed between June and August 2018 has risen sharply. Next is the elaboration of the main problems.

\section{A. Inherent Defects and Wrong Positioning of Peer to Peer Lending Industry Under Institutional Factors}

In the Internet financial market, China adopts the general idea of avoiding credit risk and solving information asymmetry. Due to the incomplete personal credit system and credit rating, the problem of information asymmetry still exists, although the practice of financial disintermediation in Internet finance has led to the unification of centralized payment system and individual mobile payment. Peer to peer lending platform mainly uses the Internet as a medium to connect investors and financiers. As investors, they know little about the real credit situation of the platform, whether the information released by the financier is true and reliable, the economic strength of the financier, and the objective situation of the development of the industry. In this case, investors are often in a weak position. It is very easy for them to be misled by false information and lead to investment failure. The peer to peer lending platform is helpless even if it wants to avoid such risks as it has not been connected to the credit system of People's Bank of China, so it is difficult to verify the authenticity and legitimacy of the material and information provided by the borrowers. Information resources sharing between the platforms is not realized, so it is very easy for the same borrower applies for registration of different accounts on different the same platform for loans several times. The series of problems caused by the information asymmetry and opacity has great risk to the security of peer to peer lending platform development.

In view of the slow growth of the entire lending industry from 2015 to 2018, some peer to peer lending platforms, in order to attract more customers and increase the turnover of the platform, usually take use of the lack of financial knowledge of ordinary investors to carry out some irrational "cost-protection propaganda" or even fraudulently add the terms with "guaranteed appearance" — the platform guarantee the principal and interest and its return of the investor with the platform's own funds. [4] As a result, the peer to peer lending platform has become a guarantee company in disguise, and participates in the lending process as a third party, which deviates from its positioning principle as a neutral information platform. Under the slogan of "guaranteed capital and interest", the transaction risk of borrowing is transferred to the peer to peer platform. [5] Once a large-scale default of the financiers occurs, it will largely lead to the rupture of the fund chain of the lending platform and trigger the credit crisis. The means of "guaranteed capital and interest" make the investors unable to judge the risk of loans by the rate, which is not conducive to the benign development of China's peer to peer lending platform market. And many platforms ignore the financiers credit and property status in operation, and have the same interest rate standards for different financing parties in all industries, so "a clean cut" of operation ignores the risk differences behind different projects, and makes investors in a highly dangerous position because he does not pay attention to the evaluation and judgment of the creditworthiness of the financier.

\section{B. Incomplete Technology Leads to the Operation Risk of Peer to Peer Lending Platform}

Peer to peer is a kind of lending operation mode produced by the development of the Internet. However, because the Internet in China has not been in line with the international standards for a long time, the top information technology is still lagging behind that of developed countries, which makes the scale of peer to peer lending platform expand sharply on the one hand, but on the other hand, the operating system used has technical shortcomings. The technical risk leads to the failure of transactions and withdrawal even both investors and financiers have agreement. Some peer to peer lending platforms know that the system they use has technical vulnerabilities that can easily lead to transaction payment risk, but they still use the system because of lucky psychology and cost considerations, which has buried a great security risk to the transaction. 
These are the alarm bells for the entire industry supervision. Any technology loopholes or regulatory deficiencies may have a very high risk of leakage in the user positioning, screening, risk pricing, demand auditing, call in arrears and other high-risk processes. If there are illegal ones attack the above-mentioned platforms with problem maliciously, it will not only make the investment information of the investor be stolen illegally, but also make the fund flow information of lending platform be maliciously leaked and illegally utilized as there is technical vulnerability of peer to peer lending platform system, resulting in the challenge of the normal operation of the whole peer to peer lending industry. [6]

\section{External Environment: the Crisis Behind the Prosperity Bubble}

By the end of August 2018, the transaction volume of peer to peer lending of Beijing, Shanghai, Guangdong, Zhejiang, Shandong and Jiangsu were among the top six, occupying most of the country's markets, and Hongling Capital, Tuandai and Madai Fortune were among the top three in terms of loan transactions, with a sharp contrast of huge difference of the rich and the poor between regions and industries. Due to the continuous decline of the overall peer to peer lending industry, some small and medium-sized platforms unilaterally pursue the climbing rate of loan balance, ignoring the pressure of high payment and the emerging risk of receipt. Many platforms fraud or run away in the event of a breakdown in the capital chain, and shut down or make financiers having difficulty in withdrawing to avoid legal sanctions. In addition, as platforms with problems are exposed more to the public, investors with lower risk appetite will consider putting security first while actively choosing platforms with better security but lower yields when transferring funds, which will also lead to a decline in the overall yield of the industry.

At present, with the new platform of diversified backgrounds constantly on-line, there is a considerable grey area in the industry supervision and relevant legislative provisions. Although the current legislation has set a legal line for private creditor's rights financing with the crime of issuing securities without authorization and the crime of absorbing public deposits in disguised form, there is no corresponding legal system, which will easily lead to the risk of capital pool. Against the background that Chinese economy is in the growing pains of structural adjustment and upgrading, a series of platform credit crises will arise if the funds in the venture capital pool are not enough to repay investors' losses. Secondly, the margin of the financier and the protection fund of the investor are sealed in the account on the platform. [7] If it is illegally exploited by some bad platforms, the platform can still compensate by absorbing new funds through fraudulent practices such as covering up real financial conditions, even if bad debts erupt on a large scale or cash flow problems occur. A break in the capital chain is likely to cause the platform to collapse instantly, leaving investors being trapped and investors who are still in the dark losing everything.

\section{SugGeStions For THE HeAlthy DEVELOPMENT OF PEER TO PEER LENDING INDUSTRY}

\section{A. Promoting the De-guarantee of Peer to Peer Lending Platforms}

To promote the return of peer to peer lending platform to information intermediary, it is necessary to take open and transparent capital management, standardized credit system and strong information disclosure measures as the basic conditions. People cannot change the flow of funds at will, nor can they control the receipt and payment of the funds of both investors and financiers and make mismatches in the amount and duration of the pool of funds. [8] In order to realize the de-guarantee of peer to peer lending platform, people must strengthen the construction of social credit system to lay a good foundation for its healthy and sustainable development. As the peer to peer lending platform does not have the authority to inquire the personal credit system of the central bank like the banking financial institutions, the information asymmetry between the platforms, the platforms and the users is still serious due to the lack of effective information sharing mechanism. In view of the above problems, the government departments concerned should strengthen the construction of the credit rating system of the peer to peer lending industry, encourage the private institutions to establish the lending credit rating system to strengthen the sharing of effective information between platforms [9], increase policy support for the credit rating industry, and provide correct guidance for the improvement of the third-party credit rating mechanism of the industry.

Internet financial investors generally lack the ability to audit financing projects offline. The credibility of the information displayed by the platform depends largely on the perfection of the social credit system. Although the personal and corporate credit service provided by the central bank credit center is in the process of optimization, and the central bank has begun to guide private capital to establish a credit system for individuals and enterprises, information access institutions have gradually expanded from banks to small and micro financial institutions, it is still far from perfect social credit system. [10] It should be made clear that the sources of information matching the credit demand of the peer to peer lending industry also include some nontraditional financial information generated by social media, e-commerce platforms and other institutions. If these nontraditional financial institutions are organized to establish a unified standard of information and data, the unofficial credit reporting system will be a useful supplement to the official ones to make the credit reporting system more efficient and perfect. A comprehensive rating of all credit activities of the units carried out in the society can be conducted by individuals. These credit activities include not only traditional banking businesses, but also personal credit data from social media to e-commerce platforms, such as Jingdong Baitiao and Ant Check Later of Alipay. Finally, the entire credit system should be unified, and be open to traditional financial industries such as banks and other financial leasing platforms at the same time. 


\section{B. Strengthening Data Protection and Supervision of Peer to Peer Lending Industry}

The peer to peer lending industry relies on the Internet, so the data security and information protection of users is particularly important. The enterprises of the peer to peer lending should strengthen the construction of information encryption technology, patch the explicit technical vulnerabilities while preventing the hidden ones and adopt a variety of ways to authenticate to achieve the security protection of personal information data and investment and financing transactions contracts. In the case of data security, user's transactions should be deeply analyzed to promote the development of Internet financial innovation with scientific and technological progress. Relying on artificial intelligence, cloud computing and other technologies in the context of large data, strictly control potential financial risks and strive to achieve anti-fraud in the Internet finance field.

At present, most domestic peer to peer lending platforms have established a "blacklist" system to publicize the financiers with malicious arrears of funds, and prohibit their new account to issue financing information before its arrears are paid off. However, the current "blacklist" system is established by each peer to peer lending platform and lacks of information exchange with other private financial leasing channels, which leads to the insufficient information circulation and thus reduces the availability of information. In order to resist malicious financing and guard against financing risks, all peer to peer lending platforms should jointly establish a "blacklist" database to realize information sharing, input the information of malicious defaulting borrowers into the credit system to realize the exchange of honest records, and avoid further credit services to illegal financier listed on "blacklist". Similar systems have been implemented preliminarily. Taking Alipay as an example, Alipay, as a representative of the third-party platform, can establish a "blacklist" exchange mechanism with traditional financial institutions through its huge trading volume and secure database and becomes a formal financial institution through the Government's "Non-financial Institutions Payment Service Management Measures". In order to cooperate with commercial banks and other traditional financial institutions, the peer to peer lending platform should be recognized by the regulatory authorities and regulated by policies. It can be supplemented by classified supervision on the basis of insisting on the "bottom line thinking" to encourage the peer to peer lending platform to continue to innovate its business model. The relevant departments should also supervise the information disclosure mechanism of peer to peer lending platform, requiring the platform to provide the true information of the financing party or the guarantor in strict accordance with the "Guidelines for Information Disclosure of Financing Guarantee Companies" issued by the China Banking Regulatory Commission; and the platforms for guaranteeing the principal and interest with the reserve fund are required to publicly compensate the coverage and reserve balance. For the platform that provides the guarantee of principal and interest by means of insurance, its underwriting capacity and scope of protection should be strictly supervised.

\section{Improving the Risk Prevention Laws of Peer to Peer Industry and the Dispute Settlement Mechanism}

Perfect legal protection system is a powerful basis for investors to safeguard their rights. The relevant departments should establish a complete system of provisions to protect investors' rights and interests according to the development of peer to peer industry. Although the "Notice on Compliance Inspection of Peer to Peer Lending Institutions" issued in August, 2018 explicitly stipulates that people should strictly follow the "1 + 3" system framework to combine the check and correction and reform radically, there is still room for greater progress in supporting legislation. One is to formulate access standards and self-regulatory conventions for the peer to peer lending industry - by examining the qualifications of the financiers one by one, to eliminate possible factors of bad debts. The wise way is to judge the legitimacy and rationality of the use of financing to strengthen pre-loan audits, and retreat immediately once there is illegal on-line; the second is to clearly stipulate the rights and obligations of both parties involved in the transaction of the peer to peer lending platform, and to set up a maximum loan quota - for loans to small and micro enterprises that often occur in the financing process, the maximum limit of loans to them linked to their monthly turnover can be reached by referring to Article 18 of the Measures for the Pilot Management of Consumer Finance Companies to reduce the financial risk of peer to peer lending platforms.

On the level of dispute mediation, a diversified financial dispute resolution mechanism should be established on the basis of the current investor rights relief system. The judicial relief mechanism, the financial consumption dispute mediation mechanism and the FOS mechanism should be combined to form a diversified financial dispute resolution system to promote the construction of the final relief barrier for protecting investors' rights and interests by joint efforts of financial institutions and supervision departments. First of all, people should further optimize the complaint handling process from the point of the peer to peer lending platform. Especially in the process of accepting complaints, investors lending disputes should be allowed to complain to the platform first, then to the industry association, then to the Internet financial supervision department, and finally to apply for arbitration or litigation. Secondly, on the level of Internet financial supervision departments, people should bring the complaint handling mechanism into the daily supervision category of relevant departments by carrying out reasonable and effective supervision guidelines. Finally, at the level of judicial settlement, people should improve the efficiency of dispute resolution, optimize the litigation process, and give special care to investors, who are in a disadvantaged position, in the setting of burden of proof in peer to peer lending disputes.

\section{CONCLUSION}

As China's peer to peer lending industry is developing and transforming, it is urgent for the government to improve the regulatory measures and corresponding laws and regulations. This paper is expected to provide references for 
relevant legislation to be implemented, with a view to attracting more valuable advice.

\section{REFERENCES}

[1] Peng Bing. Research on Supervision Mode of Peer to Peer Lending. The Eighty-ninth Phase of Financial Law.

[2] Yang Dong. Legal Regulation of Internet Finance Based on the Perspective of Information Tools, Chinese Social Sciences. 2015 (4).

[3] Wen Xiaoni, Wu Xiaojuan. Analysis of the Factors Affecting the Success Rate of Peer to Peer Lending - Taking PPDAI as an Example. Financial Forum. 2014 (3).

[4] Zheng Yingfei, Chen Xiaojing. Interest Protection and Investor's Response on Peer to Peer Lending Platform. Financial Forum. 2018 (1).

[5] Chen Siyuan. Research on the Protection of Consumers in Peer to Peer Lending. The Second Issue of Legal System and Society. 2018 (4).

[6] Zhang Chaoyu, Chen Fei. Research on the Alienation and Deguarantee of Peer to Peer Lending Platform. South Finance. 2018 (1).

[7] Ba Shusong, HouXinyu, Zhang Shuai. Research on Survival Mode and Policy Simulation of Peer to Peer Lending Platform Based on Survival Model. Contemporary Finance and Economics. 2018 (1).

[8] Yang Fan. Risk Control and Regulatory Transformation of Peer to Peer Lending Platform in China. Modern Business. 2018 (1).

[9] Jiu Baixue. Analysis of Risk and Prevention of Peer to Peer Lending Platform. Legality Vision. 2018 (2).

[10] Lei Jian. Development Status, Problems and Regulatory Countermeasures of Peer to Peer Lending Industry in China. International Finance. 2014 (8). 